\title{
The current state of knowledge about the dipping and non-dipping hypertension
}

\section{Zbigniew Dubielski', Michał Zamojski', Bartosz Wiechecki', Olga Możeńska', Monika Petelczyc², Dariusz Artur Kosior ${ }^{3}$}

\author{
${ }^{1}$ Department of Cardiology and Hypertension, Central Clinical Hospital of the Ministry of Interior, Warsaw \\ ${ }^{2}$ Faculty of Physics, Warsaw University of Technology, Warsaw \\ ${ }^{3}$ Faculty of Medicine, Lazarski University, Warsaw, Poland \\ Department of Cardiology and Hypertension, Central Research Hospital of the Ministry of Interior \\ Department of Applied Physiology, Mossakowski Medical Research Center, Polish Academy of Sciences, Warsaw, Poland
}

\begin{abstract}
Ambulatory blood pressure monitoring provides information about the day-night blood pressure profile, which can be divided into dipping and non-dipping pattern. Non-dipping hypertension is recently thought to have increased cardiovascular risk and outcomes than dipping hypertension. The dipping pattern is explained by physiological changes in circadian rhythm, while the pathomechanism of non-dipping hypertension is not fully understood. Is it considered to be a result of many factors, such as: sympathetic nervous system overactivation, which can be accompanied by impaired parasympathetic nervous system response, obesity, concurrent diabetes mellitus and metabolic syndrome. Moreover abnormalities of hormones levels such as melatonin, catecholamines, thyroid and parathyroid hormones are connected to occurrence of non-dipping hypertension. Other widely discussed problem is obstructive sleep apnoea and its influence on circadian rhythm changes. Also dysfunction in activity of renin-angiotensin-aldosterone axis is thought to cause non-dipping pattern. There are some studies that indicate on role of inappropriate sodium intake in mentioned pathology. The chronic kidney disease and relationship with non-dipping hypertension will be also described. The last considered factor is influence of age on the development of non-dipping hypertension. key words: circadian blood pressure profile, blood pressure regulation, chronobiology, nocturnal hypertension, non-dipping pathomechanism
\end{abstract}

Arterial Hypertens. 2016, vol. 20, no. 2, pages: 33-43

DOI: $10.5603 / A H .2016 .0007$

\section{Introduction}

Elevated blood pressure (BP) is recently thought to be one of the most important risk factors of cardiovascular diseases [1]. Therefore it is not surprising that there are a lot of studies about the pathology, complications and treatment of hypertension [2-4]. In this review we will focus on pathology of hypertension taking into account its dipping and non-dipping pattern. This is one of the fastest growing branches of interest in the field of hypertension.
Type of circadian BP rhythm is defined as proportion of the nocturnal average BP fall to daytime average $\mathrm{BP}$ value. If it is less than $10 \%$, then it is referred to as a non-dipping pattern, if it is $10-20 \%$, it is referred to as dipping pattern [1]. Nocturnal average $\mathrm{BP}$ fall above $20 \%$ of daytime average BP values is referred to as extreme dipper pattern. The increase instead of decrease of average BP values between average nighttime and daytime values is known as reverse dipper pattern $[5,6]$.

\footnotetext{
Address for correspondence: Dariusz Artur Kosior, MD, PhD, FESC, FACC

Faculty of Medicine, Lazarski University, Warsaw, Poland

Department of Cardiology and Hypertension, Central Research Hospital of the Ministry of Interior

Department of Applied Physiology, Mossakowski Medical Research Center, Polish Academy of Sciences, Warsaw, Poland

tel.: (+48 22) 508-16-70, faks: (+48 22) 508-16-80

e-mail: dariusz.kosior@cskmswia.pl; s.iadariusz@upcpoczta.pl
} 


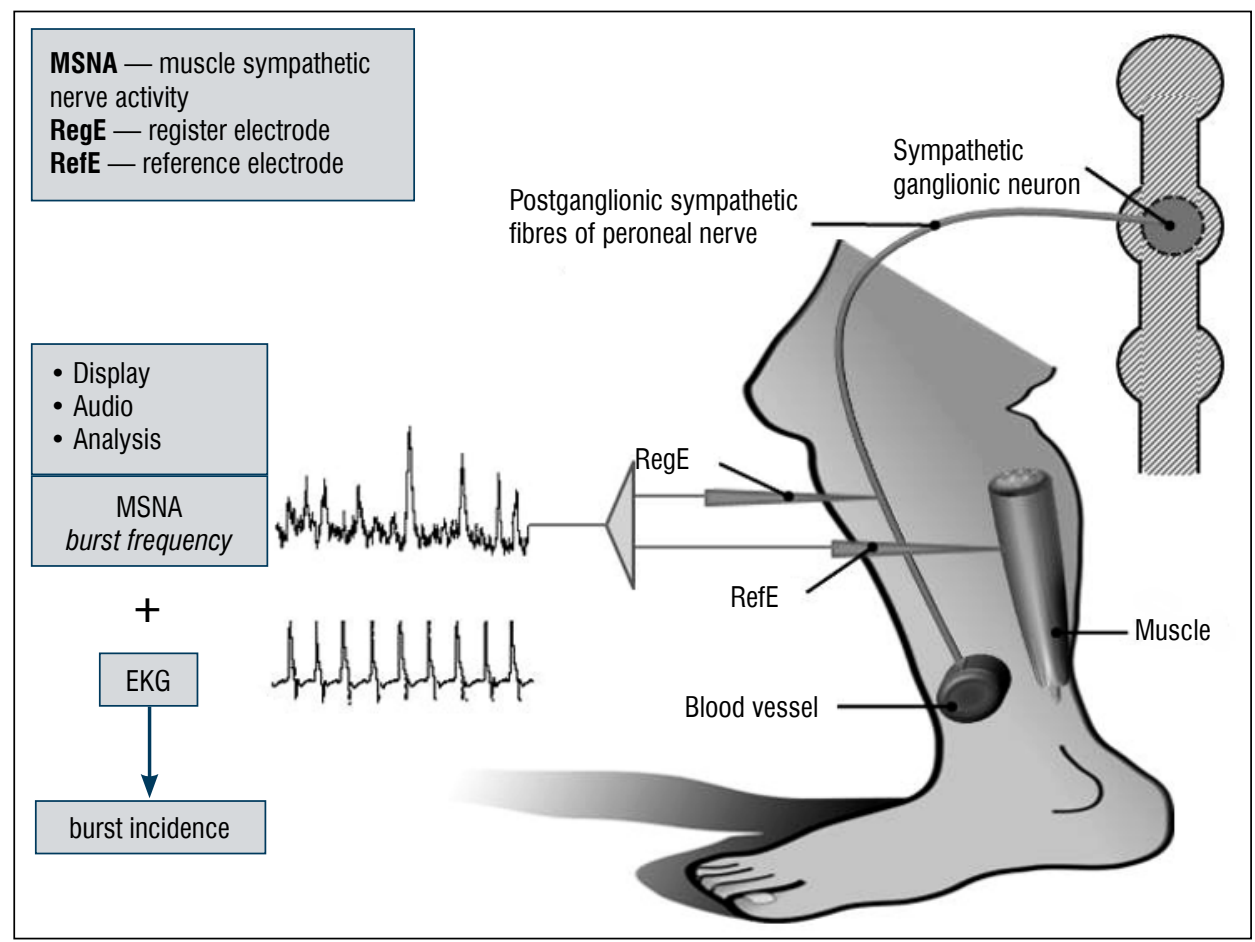

Figure 1. Microneurography is neurophysiological, invasive, direct method of postganglionic sympathetic nerves electric activity measuring. Usually it is used to visualize and record muscle sympathetic nerve activity

This division refers either to normotensive or hypertensive patients. To gather information about nocturnal BP fall ambulatory blood pressure monitoring $(\mathrm{ABPM})$ is conducted. The data are collected from 24-hour period, which can be lengthened even up to 48 hours in order to increase reproducibility of the results. The ABPM is now accepted to have greater prognostic value than office BP measurements $[7,8]$. The dipping pattern is explained by physiological sympathetic activity decrease and parasympathetic activity increase during the night [9]. This physiological change between day and night autonomic nervous system (ANS) activity is connected to suprachiasmaticus nucleus and its ability to generate circadian rhythm [10-12]. On the other hand, the non-dipping pattern is connected with disorders and disturbances of the circadian rhythm as well as in situation where effects of regular circadian rhythm are too weak to manifest in front of existing pathology [12-21].

\section{Autonomic nervous system}

Despite many years of study on non-dipping pattern there is no one clear mechanism of its pathology. The ANS is believed to play the major role in non-dipping profile of hypertension $[9,13,14,22,23]$. To confirm such theory the ANS activity is measured and compared between dipper and non-dipper pa- tients [12-15]. There are techniques that allow measurement only the sympathetic nervous system (SNS) activity or SNS and parasympathetic nervous system (PNS) activity [12-15, 24-28]. Modern medical technology offers direct and indirect SNS activity measurements [24-28]. One of them is measurement of the urinary concentration of norepinephrine (NE), the SNS neurotransmitter [29]. The Arita et al. found a correlation between the nocturnal fall in BP and the urinary NE concentration [15]. This correlation suggests that decrease in BP was associated with reduction in SNS activity [15]. Described method has some limitations, first one being that it provides information about the general SNS activity without information about regional ones [30]. Note that local SNS activity may increase, decrease or present no changes in different regions simultaneously. The regional SNS activity monitoring of particular organs (such as heart, kidneys, vessels) may be useful in localizing the cause and defining mechanism of blunted night BP drop [31]. The second limitation of the indirect measurement of SNS activity by the concentration of $\mathrm{NE}$ in urinary is its dependence of concentration of NE on its clearance from plasma [29]. Grassi et al. conducted a study on hypertension population and revealed negative correlation between the level of SNS activity and the magnitude of nocturnal BP [14]. They used microneurography, direct measurement of muscle sympathetic nerve activity [14] (Fig. 1). 
Hojo et al. conducted a study which purpose was to show the correlation between disturbances in SNS and PNS activity by using the power spectral analysis of R-R interval [13]. The spectral components of analysed signal are related to different physiological mechanisms. Power spectrum of low frequency is related to SNS, PNS and renin-angiotensin system, while spectrum of high frequency (HF) reflects the efferent parasympathetic activity at the cardiac level and the low frequency to high frequency spectrum ratio is an index of sympathovagal balance at the cardiac level [13]. The authors revealed positive correlation in hypertensive patients between 24-hrs LF/ HF power ratio and the percentage of nocturnal systolic BP reduction [13]. Results from all mentioned studies indicated the role of altered ANS activity in the occurrence of non-dipping hypertension pattern [13-15]. The first and the second one demonstrated the connection between excessive sympathetic activity and decreased nocturnal BP reduction, which correlated with non-dipping hypertension pattern $[14,15]$. The third study showed an influence of disturbed sympathovagal balance on decreased reduction of nocturnal BP [13]. These results indicate the role of abnormal circadian rhythm of ANS on pathogenesis of non-dipping pattern. Okamoto et al. performed studies on patients with pure autonomic failure who had low and fixed sympathetic activity [12]. They suggested that jet another theory of pathogenesis of non-dipping pattern may be the inability to modulate sympathetic activity [12].

\section{Orthostatic hypotension}

Changes in body posture (horizontal to vertical) force our organism to adapt to different conditions. Autonomic nervous system is responsible for these adaptations [32]. The afferent autonomic nerves are activated and induce the baroreceptors unloading. The efferent sympathetic outflow and vasoconstriction is subsequently increased in order to increase venous return and keep resting BP value [33]. Impairment of this compensatory mechanism due to autonomic dysfunction results in orthostatic hypotension [32]. Very often patients with orthostatic hypotension may develop the supine hypertension which lead to non-dipping hypertension [34].

\section{Obesity}

The rapidly rising prevalence of obesity in highly developed countries has become the great challenge to modern health care system [35]. Interlink between obesity and hypertension is well known both in adults and children. Overweight is a creditable risk factor of hypertension development [36]. There is a significant similarity between mechanism of obesity-induced hypertension and non-dipping causes considered in different studies [37-41]. Pathological factors of increased BP in obese individuals that may play role in impaired nocturnal BP drop include: SNS activation which is suggested as crucial, altered kidney functions, obesity-driven hormones elevation, endothelial dysfunction and vascular structural changes [16]. Moreover, obesity, increased BMI, visceral fat and neck circumference are the most established risk factors for occurrence of obstructive sleep apnoea [42].

\section{Sympathetic nervous system activation}

Autonomic nervous system activity changes may be essential for blunted nocturnal BP reduction [9, 13, 14, 22, 23]. Several studies provide evidence of SNS activation in obese patients and those with high-caloric intake $[43,44]$ High muscle SNS activity were detected by microneurographic methods (direct evidence) [43]. Plasma norepinephrine concentration and rise of norepinephrine turnover in peripheral tissues correlated positively with level of caloric intake (indirect evidence) [44].

Obesity may lead to increased rennin-angiotensin-aldosterone system (RAAS) activity, hyperinsulinaemia, impaired baroreceptor sensitivity and increased free fatty acids circulation and adipokines level [43, 45-47]. These factors are considered as those which result in increased sympathetic activity [48-51]. Animal models with high fat and carbohydrate intake developed significant rise in BP due to intensified peripheral alpha-1- and beta-adrenergic receptors sensitivity [52]. Corresponding results were reported in human studies, where BP of obese patients after one month of alpha- and beta-adrenergic receptors pharmacological blockade was noticeably more reduced than BP of lean ones [53]. It have also been noticed that abdominal obesity cause greater SNS activation than peripheral or subcutaneous obesity, though reason of this difference remains unknown [54].

\section{Renal mechanism}

Physiological balance of diuresis and natriuresis is disturbed in obese patients [55]. Sodium retention in obese patients is mainly caused by increased renal sodium reabsorption, and results with hypertensive adjustment of pressure natriuresis [56]. Excess weigh may be also associated with histological changes in 
renal medulla that compress renal tubules, reduce their cross-section, which causes prolongation of the time given for sodium reabsorption [57].

Positive correlation between levels of plasma renin activity, plasma angiotensinogen, angiotensin II, aldosterone and obesity factor has been observed $[58,59]$. Independently of fluid and sodium retention, this correlation can be explained with fat that surrounds kidneys and generates pressure inducing renin secretion [57].

\section{Leptin}

Leptin is considered as a mediator of SNS activation $[56,60]$. Its amount of secretion from adipose tissue stays in direct proportion with adipose tissue mass [47]. After passing blood-brain barrier leptin binds to hypothalamus and brainstem, where it suppresses hunger drive and stimulates SNS [61]. SNS activation appears to mediate leptin-induced BP elevation, since after overall alpha and beta adrenergic blockade previous BP elevating effect of leptin is abolished [62]. This peptide hormone plays great role in modulating melanocortins production in central nervous system [63]. Leptin activity stimulates expression of pro-opiomelanocortin in hypothalamus, which in turn directly increases production of a melanocyte-stimulating hormone (MSH) [63]. Effects of MSH-3 and MSH-4 receptors blockade on rats are similar to those observed during alpha and beta-adrenergic blockade [64]. It seems that pro-opiomelanocortin-melanocortin 4 receptor system is necessary for leptin-induced BP elevation [65].

\section{Diabetes mellitus and metabolic syndrome}

Patients with diabetes mellitus also have higher risk of developing non-dipping hypertension $[17,66]$. Spallone et al. showed that patients with neuropathic type 2 diabetes have blunted nocturnal BP decline [67]. The same correlation was found in type 1 diabetes patients with autonomic neuropathy [17]. The reduced vagal tone is suggested explanation of influence of autonomic neuropathy on decline in nocturnal BP fall. Reduced vagal tone causes increased cardiac output [67]. Hypertension development in patients with insulin resistance and hyperinsulinaemia is explained by anti-diuretic effect of insulin, activation of SNS, impaired endothelium-dependent vasodilatation, effect on vascular smooth muscle growth by insulin and augmented response to endogenous vasoconstrictors [68]. Insulin also affects kidney, which is manifested by increased sodium reabsorption [69]. Related effect of described abnormalities is present in diabetes mellitus and contributes to the non-dipping hypertension pattern which we often diagnose in such patients [41].

Insulin resistance is the underlying mechanism of metabolic syndrome (MS) and previously described insulin resistance-induced hypertension [70]. Tartan et al. showed that high MS-Score predicted non-dipping $\mathrm{BP}[71,72]$. Hyperuricaemia is suggested to be a signal for clinician to intensify inspection of BP control [18]. Risk analysis revealed that hyperuricaemia is a risk factor of non-dipping hypertension development [18].

\section{Hormones}

\section{Thyroid hormone}

There is strong association between variation in serum thyroid hormones level and the occurrence of cardiovascular system diseases [73]. Free triiodothyronine directly affects smooth muscle cells as a vasodilator and free thyroxine induces relaxation of skeletal muscles resistance arterioles [74-76]. Hypothyroidism may cause impairment of muscle vasodilatation, endothelial dysfunction, hypercholesterolaemia associated with a reduction in aortic compliance and is also considered a risk factor for atherosclerosis [62, 77-81]. The fifth Tromsø study which included 5872 patients demonstrated modest, but significant positive association between serum thyroid-stimulating hormone range and BP levels [82]. Although results suggested that thyroid hormones played a role in regulating $\mathrm{BP}$, it did not consider possible correlation between hormones levels and non-dipping hypertension. That type of correlation was reported by other study that indicated a graded independent negative relation between levels of free triiodothyronine and the risk of non-dipping hypertension [72, 74].

The relation between hypothyroidism and non-dipping hypertension might be caused by influence of thyroid hormones on sympathetic nervous system, probably by regulating adrenergic receptor function and their density [83-85]. The number of beta-adrenergic receptors is decreased, therefore, alpha-adrenergic responses increase what might result in the increase in systemic vascular resistance [86]. Probably, the endothelial dysfunction related to thyroid impairment plays an important role in the prevalence of sustained hypertension [87].

\section{Parathyroid hormone}

In the study performed by Kanbay et al. 190 patients were divided into 2 groups: dippers and non-dip- 
pers. The analysis provided evidence that the second group had higher levels of parathyroid hormone (PTH), phosphate and calcium X phosphate product [88]. Those findings suggest correlation between higher levels of PTH and phosphate in hypertensive patients with normal mineral metabolism and glomerular filtration rate $>60 \mathrm{ml} / \mathrm{min}$ and the increased risk of having non-dipping hypertension pattern [88].

Primary hyperparathyroidism is correlated with high prevalence of hypertension [89]. Study by Fliser et al. demonstrated that in healthy volunteers subacute administration of physiological doses of human 1.34-parathyroid hormone causes BP increase [90]. Administration of 1.34-parathyroid hormone raised ionized calcium and intracellular calcium concentration of platelets [90]. Mechanism of BP increase may be a result of higher level of PTH, which causes a rise in intracellular ionized calcium in vascular smooth muscle cells [91, 92]. Investigation by Feldstein $e t$ al. revealed independent positive correlation between ionic calcium level and the risk of non-dipping pattern in subjects with nondialysis chronic kidney disease [93].

The function of PTH in pathogenesis of non-dipping hypertension might be related to direct effect on renin secretion [19]. Moreover, patients with primary hyperparathyroidism had the pressor response elevated as assessed in the norepinephrine test [19]. Activation of the RAAS and enhanced sensitivity to norepinephrine may contribute to hypertension prevalence and to vessels sensitization to pressor agents [19].

\section{Other hormones}

Melatonin is related to BP regulation [94]. Non-dipper patients have impaired nocturnal melatonin secretion in comparison with dippers [95]. Influence of melatonin on circadian BP profile may result from its direct effect on peripheral arteries by melatonin's antioxidative character and its interaction with the $\mathrm{Ca}^{2+}$-calmodulin complex in smooth muscle and endothelial cells, which decreases the level of $\mathrm{Ca}^{2+}$ [94]. Study by Lusardi $e t$ al. reported that exogenous melatonin ingestion can reduce BP [96]. Melatonin can alter ANS tonus [71].

Blood pressure regulation is also associated with cortisol and catecholamines [97, 98]. Impairment of the circadian BP rhythm has been reported in patients with Cushing's syndrome and pheochromocytoma [93, 99, 100]. Investigation by Krzyzanowska et al. revealed a correlation between hypopituitarism occurrence and abnormal circadian BP [101].

\section{Renin-angiotensin-aldosterone system}

Intrarenal RAAS is hyperactive in patients with essential hypertension [102]. Stimulation of the RAAS causes increased sodium and water retention. As a result, such stimulation extends blood volume. Moreover, when the RAAS is hyperactive, augmentation of peripheral vascular resistance occurs [103]. Experiments conducted mainly in rats reported that elevated intracellular sodium in neurons activates brain RAAS [104]. Angiotensin II administrated into vertebral arteries causes sympathetic activation and pressor responses [105]. Westcott et al. consider major role of aldosterone in activation of central nervous system, but this finding requires further investigations [49].

\section{Salt intake}

Series of studies proved the importance of the role of salt intake and sodium retention as hypertension risk factors, and now it is accepted as common knowledge [106-108]. Over the years concept of salt sensitivity was established as a result of observing heterogeneous responses to salt intake. It resulted in dividing patients into two groups: salt sensitive (SS) and salt resistant [109, 110]. Salt sensitivity is proved to be important also in dipping and non-dipping type of hypertension [111]. Although influence of salt intake on circadian BP rhythm has been revealed, exact mechanisms are still not clear. In a group of patients with essential hypertension in response to high salt diet (HSD) SS patients with preserved nocturnal BP decline turned to non-dippers, which was not observed in SR group $[111,112]$. Furthermore, in other study sodium restriction significantly decreased nighttime BP only in SS group [111]. Possible pathways of salt-induced non-dipping patterns are: SNS increased output, altered renal function and diminished inhibition of RAAS, impaired endothelial function, and genetic coupling factors [113-115].

Studies assessing the correlation between high salt intake and SNS activation showed that plasma norepinephrine concentration (PNEC), indirect index of SNS activity level, was elevated and significantly higher in SS patients compared with SR individuals [79]. In the face of PNEC elevation, nocturnal arousal effects of SNS may be also enhanced by not adequate urinary noradrenaline excretion, which in SS patients on HSD stays unchanged during the night and is increased in daytime [112]. Sodium intake affects RAAS and renal hemodynamic [112]. 
Table I. Salt sensitive and salt resistant patient's plasma renin activity (PRA), plasma aldosterone (PALD) and plasma angiotensin II (PAngll) levels were measured on the last day of both high and low salt intake study stages. Suppression of PRA, PALD, PAng II induced by high salt intake was poorer in SS patients. Adapted from reference [109]

\begin{tabular}{|l|c|c|c|c|}
\hline & \multicolumn{2}{|c|}{ Sodium sensitive $(\mathbf{N}=9)$} & \multicolumn{2}{c|}{ Sodium resistant (N = 14) } \\
\hline & High salt & Low salt & High salt & Low salt \\
\hline PRA $[\mathrm{ng} / \mathrm{ml}]$ & $0.6 \pm 0.2^{*}$ & $2.3 \pm 0.9^{*}$ & $0.4 \pm 0.2$ & $3.0 \pm 0.7$ \\
\hline PALD $[\mathrm{pg} / \mathrm{ml}]$ & $70.3 \pm 16.3^{*}$ & $252.2 \pm 46.0^{*}$ & $55.0 \pm 18.1$ & $271.0 \pm 51$ \\
\hline PAng II $[\mathrm{pg} / \mathrm{ml}]$ & $42.8 \pm 10.9$ & $81.6 \pm 17.0$ & $40.1 \pm 15.8$ & $82.1 \pm 14.6$ \\
\hline
\end{tabular}

As showed on Table I, plasma aldosterone level and plasma renin activity suppression was lower in SS than in SR group [109] (Table I).

Study conducted on large group of African individuals showed positive correlation between sodium urinary excretion in nighttime and level of nighttime systolic BP reduction [116]. Reduced sodium excretory capability, that occurred in SS patients, combined with HSD caused sodium overload during the day and resulted in blunted BP drop at night [59]. Night BP elevation was a compensative mechanism which increased natriuresis pressure [79]. Furthermore, patients with essential hypertension and non-dipping pattern during hydrochlorothiazide treatment, drug which increase sodium urinary excretion, showed significant reduction in both nocturnal systolic and diastolic BP, while this effect was not observed in dipping individuals [117]. The study conducted on G927R polymorphism of insulin receptor substrate-1 may help to understand association between HSD, SS and non-dipping in some patients [115].

In heterozygous carriers of G972R IRS-1, high daily salt intake resulted in significant increase in insulin level and insulin resistance [115]. Both mechanisms were considered as independent predictors and risk factors of lack of adequate nocturnal BP decline $[68,69]$. Moreover, as predicted, heterozygous carriers on HSD more frequently developed non-dipping hypertension [115].

\section{Chronic kidney disease}

There are many studies in which kidneys are described as essential organ in BP regulation and their role in pathomechanism of hypertension development is crucial [118-120]. According to National Kidney Foundation, elevated level of BP may be either a consequence or a cause of chronic kidney disease (CKD) defined as a presence of, for 3 months or more, at least one of the following criteria: kidney damage or/and GFR $<60 \mathrm{ml} / \mathrm{min} / 1,73 \mathrm{~m}^{2}$ [121]. Among 264 patients with CKD involved in in- vestigation by Fedecostante et al., approximately all $(97.8 \%)$ were hypertensive [122]. That study demonstrated also a relationship between prevalence of CKD and non-dipping pattern of hypertension. It indicated that $\mathrm{CKD}$ had direct influence on circadian BP profile [122]. That finding was in agreement with former study by Farmer $e t a l$., who reported more frequent predominance of non-dipping in subjects with CKD than in controls with essential hypertension [123]. There were also associations between worsening of renal function and non-dipping pattern rise [123]. Arterial hypertension is also common in patients after renal transplantation (it affects $60-80 \%$ of them) [124]. A strong determinant of non-dipping hypertension pattern in those patients is the Doppler-derived renal resistive index [125].

Salt sensitivity (controlled by kidneys) is a potential mechanism causing non-dipping hypertension pattern [126]. High salt sensitivity was responsible for diminished BP fall in essential hypertension and salt restriction changed non-dipping pattern into dipping [111, 127]. According to study by Fujii et al. in non-dipping salt-sensitive type of hypertension, the circadian rhythm of natriuresis is disturbed [77]. Kimura et al. suggested that both, decrease in renal sodium excretory in patients with CKD and hypertension with sodium sensitive BP had influence on circadian alterations in BP [128].

Association between CKD and hypertension may be related to the activation of tissue renin-angiotensin system [129]. Aldosterone is associated with hypertension by its impact on BP elevation, cardiac fibrosis and vascular injury [130].

Metabolic changes in CKD are the cause of calcification of the wall of arteries and are associated with increased atherosclerosis [124]. As a result, the increase of arterial stiffness is observed, causing development of high BP [9].

\section{Sleep disturbances}

According to several studies high quality sleep is suggested as crucial for dipping pattern [131]. Noc- 
turnal BP changes stay in close relation to sleep stages [132]. Years ago Portaluppi et al. extensively analysed that issue in the separate study [132]. The highest nighttime BP reduction occurred in the deepest sleep, which corresponded to 3 and 4 stage of non-rapid eye movement sleep, while during 1 , 2 stage of NREM and rapid eye movement (REM) sleep BP was significantly higher [16, 132]. Central control of respiratory mechanism and respiration oscillations were also directly associated with nocturnal BP changes [132]. During deep NREM sleep breathing becomes regular and $\mathrm{BP}$ and heart rate decrease is observed [132]. Irregular respiration, apnoea periods, hypercapnia, oxygen saturation drop are characteristic for 1,2 stage of NREM and REM sleep, which results with arousal and BP elevation $[132,133]$. Detailed study of these mechanisms may be a key to understanding association between several sleep disturbances and non-dipping pattern.

\section{Stress status and sleep quality}

Some studies revealed associations between poor sleep quality and impaired circadian BP rhythm [79, 134]. Other showed that sleep disturbances increase SNS activity and may cause blunted nocturnal BP drop [135]. The contribution of anxiety/stress disorders in decreased sleep quality was reported [79]. The examination of patients with posttraumatic stress disorders showed relationship between occurrence and severity of that disorder and lack of BP dipping [136]. Promising results were obtained from study carried out on Chinese cohort, a juxtaposition of stress and sleep quality proper assessment scales [the Perceived Stress Scale and Pittsburgh Sleep Quality Index (PSQI)] and nocturnal BP type [79]. Proportion of non-dippers, level of norepinephrine and epinephrine were higher in patients with higher PQSI and PSS score, which confirmed that stress and poor sleep quality could be reliable factors in non-dipping hypertension status. Even though controversies in the field remain $[137]^{2}$. Benign prostate hyperplasia, state in which sleep disturbances and nocturia occur, is as well in association with non-dipping pattern [138]. However, in that clinical scenario, mainly nocturia and following increase of arginine vasopressin secretion may affect directly nocturnal BP variability [139].

\section{Obstructive sleep apnoea}

Obstructive sleep apnoea (OSA) is a common disorder characterized by repetitive collapse of upper airways during sleep, resulting in recurrent apnoea episodes. Even mild OSA can manifest with transient hypoxaemia and hypercapnia, disruption of normal sleep, increased SNS output and intra-thoracic pressure swings. Impaired nocturnal $\mathrm{BP}$ decrease was noted in $48-84 \%$ patient with OSA and was associated with OSA severity $[140,141]$. Recent studies also showed 3\% increase of mean arterial pressure per 1-unit increase of oxygen desaturation index (the number of oxygen desaturations $>3 \%$ per hour of estimated sleep time) [142]. Major factors in chronically increased BP are hypoxaemia and SNS outflow [74, 93, 142]. Moreover, these effects persist even after removal of hypoxaemic factor due to altered autonomic control [143]. The possible mechanism explaining persistence of these effects includes abnormal baroreceptor reflex function and impaired chemoreflex sensitivity [20,21, 144]. Chen et al. suggested the role of endothelin (ET) in hypoxaemia-induced aroused chemoreceptor activity. Functional studies revealed chemoexcitory action of ET [145]. Continuous hypoxaemia increases expression of ET A receptor and of preproendothelin in the carotid body, therefore enhance chemoreceptor activity [146]. Changes in mean BP from apnoea to ventilation periods stays in inverse correlation with age [16]. It explains why severe apnoea component of OSA is responsible for non-dipping only in young patients, while sleep disturbances are more meaningful in elderly non-dipping OSA individuals [86].

Wolf et al. discussed several factors involved in non-dipping pattern occurrence: impaired endothelium-dependent vasodilatation, blunted nitric oxide production, oxidative stress, increased plasma asymmetric dimethyl arginine concentration, elevated levels of L-selectin, vascular cell adhesion molecule-1, intercellular adhesion molecule-1 and low-grade inflammation [147]. Studies show that continuous positive airway pressure (CPAP) therapy and lateral pharyngoplasty reduce nocturnal $\mathrm{BP}$ and significantly increase prevalence of dipping pattern in OSA patients [148-150]. Treatment procedures show importance of OSA in triggering of non-dipping development.

\section{Aging}

Age is the next factor discussed in the context of non-dipping hypertension occurrence. Staessen $e t$ al. published analysis which showed that the number of non-dippers subjects increased with age [151]. In elderly patients the circadian sleep-wake rhythm is changed due to experiencing less slow-wave sleep and more frequent occurrence of awake periods [152]. The occurrence of non-dipping hypertension in elderly patients may be also caused by decreased para- 
sympathetic nervous activity and impaired balance between sympathetic and parasympathetic nervous activity [135]. Kohara et al. suggested that atherosclerosis can participate in attenuation of ANS [153]. Furthermore, the study conducted on patients with OSA revealed that prevalence of non-dipping pattern in elderly patient group maintained higher than in younger group [86].

\section{Conclusions}

A lot of various factors are involved in development of hypertension. Its pathogenesis is associated with alteration in ANS activation e.g. disturbance in sympathetic and parasympathetic balance and changes in endocrine system. Risk factors for developing hypertension are: advanced age, obesity, diabetes mellitus, chronic kidney disease and obstructive sleep apnoea. They also correlate with the occurrence of non-dipping circadian blood pressure rhythm. Other important factor is overreaction for salt intake. The division of hypertension into dipping and non-dipping is clinically significant. Non-dippers have greater probability of cardiovascular events and have worse general prognosis. Exact pathomechanism of impairment of circadian blood pressure pattern is not fully understood and because of its importance related with raised general risk further studies are necessary.

\section{References}

1. Mancia G., Fagard R., Narkiewicz K. et al. 2013 ESH/ESC Guidelines for the management of arterial hypertension: the Task Force for the management of arterial hypertension of the European Society of Hypertension (ESH) and of the European Society of Cardiology (ESC). J. Hypertens. 2013; 31: 1281-1357.

2. Grassi G., Seravalle G., Trevano F.Q. et al. Neurogenic abnormalities in masked hypertension. Hypertension 2007; 50: 537-5342.

3. Esler M., Lambert G., Jennings G. Regional norepinephrine turnover in human hypertension. Clin. Exp. Hypertens. A. 1989; 11 (Suppl. 1): 75-89.

4. Briasoulis A., Agarwal V., Tousoulis D., Stefanadis C. Effects of antihypertensive treatment in patients over 65 years of age: a meta-analysis of randomised controlled studies. Heart 2014; 100: 317-323.

5. Fagard R.H. Dipping pattern of nocturnal blood pressure in patients with hypertension. Expert Rev. Cardiovasc. Ther. 2009; 7: 599-605.

6. European Society of Hypertension (ESH) and the European Society of Cardiology (ESC). 2013 ESH/ESC Guidelines for the Management of Arterial Hypertension. Blood Press. 2013; 22: 193-278.

7. Pickering T.G., Shimbo D., Haas D. Ambulatory blood-pressure monitoring. N. Engl. J. Med. 2006; 354: 2368-2374.

8. Verdecchia P., Angeli F., Cavallini C. Ambulatory blood pressure for cardiovascular risk stratification. Circulation 2007; 115: 2091-2093.

9. Sherwood A., Steffen P.R., Blumenthal J.A., Kuhn C., Hinderliter A.L. Nighttime blood pressure dipping: the role of the sympathetic nervous system. Am. J. Hypertens. 2002; 15: 111-118.

10. Shaw E., Tofler G.H. Circadian rhythm and cardiovascular disease. Curr. Atheroscler. Rep. 2009; 11: 289-295.
11. Biaggioni I. Circadian clocks, autonomic rhythms, and blood pressure dipping. Hypertension 2008; 52: 797-798.

12. Okamoto L.E., Gamboa A., Shibao C. et al. Nocturnal blood pressure dipping in the hypertension of autonomic failure. Hypertension 2009; 53: 363-369.

13. Hojo Y., Noma S., Ohki T., Nakajima H., Satoh Y. Autonomic nervous system activity in essential hypertension: a comparison between dippers and non-dippers. J. Hum. Hypertens. 1997; 11: 665-671.

14. Grassi G., Seravalle G., Quarti-Trevano F. et al. Adrenergic, metabolic, and reflex abnormalities in reverse and extreme dipper hypertensives. Hypertension 2008; 52: 925-931.

15. Arita M., Minami E., Nakamura C., Ueno Y., Nishio I., Masuyama Y. Role of the sympathetic nervous system in the nocturnal fall in blood pressure. Hypertens. Res. 1996; 19: 195-200.

16. Tun Y., Okabe S., Hida W. et al. Nocturnal blood pressure during apnoeic and ventilatory periods in patients with obstructive sleep apnoea. Eur. Respir. J. 1999; 14: 1271-1277.

17. Lurbe E., Redon J., Kesani A. et al. Increase in nocturnal blood pressure and progression to microalbuminuria in type 1 diabetes. N. Engl. J. Med. 2002; 347: 797-805.

18. Tutal E., Sayın B., Ertugrul DT., Ibis A., Sezer S., Ozdemir N. Is there a link between hyperuricemia, morning blood pressure surge, and non-dipping blood pressure pattern in metabolic syndrome patients? Int. J. Nephrol. Renovasc. Dis. 2013; 6: 71-7.

19. Gennari C., Nami R, Gonnelli S. Hypertension and primary hyperparathyroidism: the role of adrenergic and renin-angiotensin-aldosterone systems. Miner. Electrolyte Metab. 1995; 21:77-81.

20. Parati G., Di Rienzo M., Bonsignore M.R. et al. Autonomic cardiac regulation in obstructive sleep apnea syndrome: evidence from spontaneous baroreflex analysis during sleep. J. Hypertens. 1997; 15: 1621-1626.

21. Narkiewicz K., Pesek C.A., Kato M., Phillips B.G., Davison D.E., Somers V.K. Baroreflex control of sympathetic nerve activity and heart rate in obstructive sleep apnea. Hypertension 1998; 32: 1039-1043.

22. Omboni S., Smit A.A., van Lieshout J.J., Settels J.J., Langewouters G.J., Wieling W. Mechanisms underlying the impairment in orthostatic tolerance after nocturnal recumbency in patients with autonomic failure. Clin. Sci. (Lond). 2001; 101: 609-618.

23. Mann S., Altman D.G., Raftery E.B., Bannister R. Circadian variation of blood pressure in autonomic failure. Circulation 1983; 68: 477-483.

24. Yucha C.B. Use of microneurography to evaluate sympathetic activity in hypertension: a brief review. Appl. Psychophysiol. Biofeedback 2000; 25: 55-63.

25. Esler M., Lambert G., Brunner-La Rocca H.P., Vaddadi G., Kaye D. Sympathetic nerve activity and neurotransmitter release in humans: translation from pathophysiology into clinical practice. Acta Physiol. Scand. 2003; 177: 275-284.

26. Lee J., Matsumura K., Yamakoshi T. et al. Validation of normalized pulse volume in the outer ear as a simple measure of sympathetic activity using warm and cold pressor tests: towards applications in ambulatory monitoring. Physiol. Meas. 2013; 34: 359-375.

27. Bosch J.A., Veerman E.C., de Geus E.J., Proctor G.B. $\alpha$-Amylase as a reliable and convenient measure of sympathetic activity: don't start salivating just yet! Psychoneuroendocrinology 2011; 36: 449-453.

28. Esler M., Jennings G., Korner P., Blombery P., Sacharias N., Leonard P. Measurement of total and organ-specific norepinephrine kinetics in humans. Am. J. Physiol. 1984; 247: E21-28.

29. Esler M. The sympathetic system and hypertension. Am. J. Hypertens. 2000; 13: 99S-105S.

30. Esler M., Kaye D. Sympathetic nervous system activation in essential hypertension, cardiac failure and psychosomatic heart disease. J. Cardiovasc. Pharmacol. 2000; 35 (7 Suppl. 4): S1-7.

31. Esler M. The sympathetic nervous system through the ages: from Thomas Willis to resistant hypertension. Exp. Physiol. 2011; 96: 611-622.

32. Freeman R., Wieling W., Axelrod F.B. et al. Consensus statement on the definition of orthostatic hypotension, neurally mediated syncope and the postural tachycardia syndrome. Auton. Neurosci. 2011; 161: 46-48. 
33. Smit A.A., Halliwill J.R., Low P.A., Wieling W. Pathophysiological basis of orthostatic hypotension in autonomic failure. J. Physiol. 1999; 519: 1-10.

34. Briasoulis A., Silver A., Yano Y., Bakris G.L. Orthostatic hypotension associated with baroreceptor dysfunction: treatment approaches. J. Clin. Hypertens. (Greenwich). 2014; 16: 141-148.

35. Hossain P., Kawar B., El Nahas M. Obesity and diabetes in the developing world - a growing challenge. N. Engl. J. Med. 2007; 356: $213-215$

36. Garrison R.J., Kannel W.B., Stokes J., Castelli W.P. Incidence and precursors of hypertension in young adults: the Framingham Offspring Study. Prev. Med. 1987; 16: 235-251.

37. Kang Y.S. Obesity associated hypertension: new insights into mechanism. Electrolyte Blood Press. 2013; 11: 46-52.

38. Hall J.E., da Silva A.A., do Carmo J.M. et al. Obesity-induced hypertension: role of sympathetic nervous system, leptin, and melanocortins. J. Biol. Chem. 2010; 285: 17271-17276.

39. Kotsis V., Stabouli S., Papakatsika S., Rizos Z., Parati G. Mechanisms of obesity-induced hypertension. Hypertens. Res. 2010; 33: 386-393.

40. Fabbian F., Smolensky M.H., Tiseo R., Pala M., Manfredini R., Portaluppi F. Dipper and non-dipper blood pressure 24-hour patterns: circadian rhythm-dependent physiologic and pathophysiologic mechanisms. Chronobiol. Int. 2013; 30: 17-30.

41. Kanbay M., Turgut F., Uyar M.E., Akcay A., Covic A. Causes and mechanisms of nondipping hypertension. Clin. Exp. Hypertens. 2008; 30: 585-597.

42. Carter R., Watenpaugh D.E. Obesity and obstructive sleep apnea: or is it OSA and obesity? Pathophysiology 2008; 15: 71-77.

43. Grassi G., Seravalle G., Cattaneo B.M. et al. Sympathetic activation in obese normotensive subjects. Hypertension 1995; 25: 560-563.

44. Landsberg L., Krieger D.R. Obesity, metabolism, and the sympathetic nervous system. Am. J. Hypertens. 1989; 2: 125S-132S.

45. Ruano M., Silvestre V., Castro R. et al. Morbid obesity, hypertensive disease and the renin-angiotensin-aldosterone axis. Obes. Surg. 2005; 15: 670-676.

46. Martyn J.A., Kaneki M., Yasuhara S. Obesity-induced insulin resistance and hyperglycemia: etiologic factors and molecular mechanisms. Anesthesiology 2008; 109: 137-148.

47. de Courten M., Zimmet P., Hodge A. et al. Hyperleptinaemia: the missing link in the, metabolic syndrome? Diabet. Med. 1997; 14: 200-208.

48. Taddei S., Virdis A., Mattei P., Favilla S., Salvetti A. Angiotensin II and sympathetic activity in sodium-restricted essential hypertension. Hypertension 1995; 25: 595-601.

49. Westcott K.V., Huang B.S., Leenen F.H. Brain renin-angiotensin-aldosterone system and ventricular remodeling after myocardial infarct: a review. Can. J. Physiol. Pharmacol. 2009; 87: 979-988.

50. Stepniakowski K.T., Goodfriend T.L., Egan B.M. Fatty acids enhance vascular alpha-adrenergic sensitivity. Hypertension 1995; 25: 774-778.

51. Anderson E.A., Balon T.W., Hoffman R.P., Sinkey C.A., Mark A.L. Insulin increases sympathetic activity but not blood pressure in borderline hypertensive humans. Hypertension 1992; 19: 621-627.

52. Rocchini A.P., Yang J.Q., Gokee A. Hypertension and insulin resistance are not directly related in obese dogs. Hypertension 2004; 43: 1011-1016.

53. Wofford M.R., Hall J.E. Pathophysiology and treatment of obesity hypertension. Curr. Pharm. Des. 2004; 10: 3621-3637.

54. Farooqi S., O'Rahilly S. Genetics of obesity in humans. Endocr. Rev. 2006; 27: 710-718.

55. Guyton A.C. The surprising kidney-fluid mechanism for pressure control — its infinite gain! Hypertension 1990; 16: 725-730.

56. Hall J.E., Brands M.W., Hildebrandt D.A., Kuo J., Fitzgerald S. Role of sympathetic nervous system and neuropeptides in obesity hypertension. Braz. J. Med. Biol. Res. 2000; 33: 605-618.

57. Hall J.E. Mechanisms of abnormal renal sodium handling in obesity hypertension. Am. J. Hypertens. 1997; 10: 49S-55S.

58. Massiéra F., Bloch-Faure M., Ceiler D. et al. Adipose angiotensinogen is involved in adipose tissue growth and blood pressure regulation. FASEB J. 2001; 15: 2727-2729.
59. Sanai T., Kimura G. Renal function reserve and sodium sensitivity in essential hypertension. J. Lab. Clin. Med. 1996; 128: 89-97.

60. Wynne K., Stanley S., McGowan B., Bloom S. Appetite control. J. Endocrinol. 2005; 184: 291-318.

61. Hall J.E., da Silva A.A., Brandon E. et al. Pathophysiology of obesity hypertension and target organ injury. In: Lip G.Y.P., Hall J.E. (eds.). Comprehensive Hypertension. Elsevier, New York 2007: 447-468.

62. da Silva A.A., do Carmo J., Dubinion J., Hall J.E. The role of the sympathetic nervous system in obesity-related hypertension. Curr. Hypertens. Rep. 2009; 11: 206-211.

63. Cone R.D. Studies on the physiological functions of the melanocortin system. Endocr. Rev. 2006; 27: 736-749.

64. da Silva A.A., do Carmo J.M., Kanyicska B., Dubinion J., Brandon E., Hall J.E. Endogenous melanocortin system activity contributes to the elevated arterial pressure in spontaneously hypertensive rats. Hypertension 2008; 51: 884-890.

65. da Silva A.A., Kuo J.J., Hall J.E. Role of hypothalamic melanocortin 3/4-receptors in mediating chronic cardiovascular, renal, and metabolic actions of leptin. Hypertension 2004; 43: 1312-1317.

66. Banskota N.K., Taub R., Zellner K., Olsen P., King G.L. Characterization of induction of protooncogene c-myc and cellular growth in human vascular smooth muscle cells by insulin and IGF-I. Diabetes 1989; 38: 123-129.

67. Spallone V., Gambardella S., Maiello M.R., Barini A., Frontoni S., Menzinger G. Relationship between autonomic neuropathy, 24-h blood pressure profile, and nephropathy in normotensive IDDM patients. Diabetes Care 1994; 17: 578-584.

68. Kotchen T.A. Obesity-related hypertension: epidemiology, pathophysiology, and clinical management. Am. J. Hypertens. 2010; 23: $1170-1178$

69. Facchini F.S., DoNascimento C., Reaven G.M., Yip J.W., Ni X.P., Humphreys M.H. Blood pressure, sodium intake, insulin resistance, and urinary nitrate excretion. Hypertension 1999; 33: 1008-1012.

70. Swislocki A.L., Hoffman B.B., Reaven G.M. Insulin resistance, glucose intolerance and hyperinsulinemia in patients with hypertension. Am. J. Hypertens. 1989; 2: 419-423.

71. Cuspidi C., Meani S., Fusi V. et al. Is the nocturnal fall in blood pressure reduced in essential hypertensive patients with metabolic syndrome? Blood Press. 2004; 13: 230-235.

72. Tartan Z., Uyarel H., Kasikcioglu H. et al. Metabolic syndrome as a predictor of non-dipping hypertension. Tohoku J. Exp. Med. 2006; 210: 57-66.

73. Vargas-Uricoechea H., Bonelo-Perdomo A., Sierra-Torres C.H. Effects of thyroid hormones on the heart. Clin. Investig Arterioscler. 2014; 26: 296-309.

74. Kanbay M., Turgut F., Karakurt F. et al. Relation between serum thyroid hormone and 'nondipper' circadian blood pressure variability. Kidney Blood Press. Res. 2007; 30: 416-420.

75. Ojamaa K., Klemperer J.D., Klein I. Acute effects of thyroid hormone on vascular smooth muscle. Thyroid 1996; 6: 505-512.

76. Park K.W., Dai H.B., Ojamaa K., Lowenstein E., Klein I., Sellke F.W. The direct vasomotor effect of thyroid hormones on rat skeletal muscle resistance arteries. Anesth. Analg. 1997; 85: 734-738.

77. Giannattasio C., Mangoni A.A., Failla M. et al. Impaired radial artery compliance in normotensive subjects with familial hypercholesterolemia. Atherosclerosis 1996; 124: 249-260.

78. Ghetti FeF., Lacerda RP., Wernek FZ. et al. Impairment of muscle vasodilation during mental stress in women with subclinical hypothyroidism. Arq. Bras. Endocrinol. Metabol. 2014; 58: 750-757.

79. Huang Y., Mai W., Hu Y. et al. Poor sleep quality, stress status, and sympathetic nervous system activation in nondipping hypertension. Blood Press. Monit. 2011; 16: 117-123.

80. Hak A.E., Pols H.A., Visser T.J., Drexhage H.A., Hofman A., Witteman J.C. Subclinical hypothyroidism is an independent risk factor for atherosclerosis and myocardial infarction in elderly women: the Rotterdam Study. Ann. Intern. Med. 2000; 132: 270-278.

81. Bruckert E., Giral P., Chadarevian R., Turpin G. Low free-thyroxine levels are a risk factor for subclinical atherosclerosis in euthyroid hyperlipidemic patients. J. Cardiovasc. Risk. 1999; 6: 327-231. 
82. Iqbal A., Figenschau Y., Jorde R. Blood pressure in relation to serum thyrotropin: The Tromsø study. J. Hum. Hypertens. 2006; 20: 932-936.

83. Ripoli A., Pingitore A., Favilli B. et al. Does subclinical hypothyroidism affect cardiac pump performance? Evidence from a magnetic resonance imaging study. J. Am. Coll. Cardiol. 2005; 45: 439-445.

84. Richelsen B., Sørensen N.S. Alpha 2- and beta-adrenergic receptor binding and action in gluteal adipocytes from patients with hypothyroidism and hyperthyroidism. Metabolism 1987; 36: 1031-1039.

85. Mancia G., Sega R., Bravi C. et al. Ambulatory blood pressure normality: results from the PAMELA study. J. Hypertens. 1995; 13: $1377-1390$

86. Sasaki N., Ozono R., Yamauchi R. et al. Age-related differences in the mechanism of nondipping among patients with obstructive sleep apnea syndrome. Clin. Exp. Hypertens. 2012; 34: 270-727.

87. Dernellis J., Panaretou M. Effects of thyroid replacement therapy on arterial blood pressure in patients with hypertension and hypothyroidism. Am. Heart J. 2002; 143: 718-724.

88. Kanbay M., Isik B., Akcay A. et al. Relation between serum calcium, phosphate, parathyroid hormone and 'nondipper' circadian blood pressure variability profile in patients with normal renal function. Am. J. Nephrol. 2007; 27: 516-521.

89. Brickman A.S., Nyby M.D. Parathyroid disease and hypertension. In: Laragh J.L., Brenner B.M. (eds.). Hypertension. 2nd edn. Raven Press, New York 1995: 89-98.

90. Fliser D., Franek E., Fode P. et al. Subacute infusion of physiological doses of parathyroid hormone raises blood pressure in humans. Nephrol. Dial. Transplant. 1997; 12: 933-938.

91. Kawashima H. Parathyroid hormone causes a transient rise in intracellular ionized calcium in vascular smooth muscle cells. Biochem. Biophys. Res. Commun. 1990; 166: 709-714.

92. Hulter H.N., Melby J.C., Peterson J.C., Cooke C.R. Chronic continuous PTH infusion results in hypertension in normal subjects. J. Clin. Hypertens. 1986; 2: 360-370.

93. Feldstein C., Akopian M., Olivieri A.O., Garrido D. Association between nondipper behavior and serum calcium in hypertensive patients with mild-to-moderate chronic renal dysfunction. Clin. Exp. Hypertens. 2012; 34: 417-423.

94. Pechanova O., Paulis L., Simko F. Peripheral and central effects of melatonin on blood pressure regulation. Int. J. Mol. Sci. 2014; 15: $17920-17937$.

95. Jonas M., Garfinkel D., Zisapel N., Laudon M., Grossman E. Impaired nocturnal melatonin secretion in non-dipper hypertensive patients. Blood Press. 2003; 12: 19-24.

96. Lusardi P., Preti P., Savino S., Piazza E., Zoppi A., Fogari R. Effect of bedtime melatonin ingestion on blood pressure of normotensive subjects. Blood Press. Monit. 1997; 2: 99-103.

97. Gorman L.S. The adrenal gland: common disease states and suspected new applications. Clin. Lab. Sci. 2013; 26: 118-125.

98. Iaccarino G., Cipolletta E., Fiorillo A. et al. Beta(2)-adrenergic receptor gene delivery to the endothelium corrects impaired adrenergic vasorelaxation in hypertension. Circulation 2002; 106: 349-355.

99. Zacharieva S., Orbetzova M., Stoynev A. et al. Circadian blood pressure profile in patients with Cushing's syndrome before and after treatment. J. Endocrinol. Invest. 2004; 27: 924-930.

100. Imai Y., Abe K., Miura Y. et al. Hypertensive episodes and circadian fluctuations of blood pressure in patients with phaeochromocytoma: studies by long-term blood pressure monitoring based on a volume-oscillometric method. J. Hypertens. 1988; 6: 9-15.

101. Krzyzanowska K., Schnack C., Mittermayer F. et al. High prevalence of abnormal circadian blood pressure regulation and impaired glucose tolerance in adults with hypopituitarism. Exp. Clin. Endocrinol. Diabetes 2005; 113: 430-434.

102. Admiraal P.J., Derkx F.H., Danser A.H., Pieterman H., Schalekamp M.A. Intrarenal de novo production of angiotensin I in subjects with renal artery stenosis. Hypertension 1990; 16: 555-563.

103. Makaritsis K.P., Liakopoulos V., Leivaditis K., Eleftheriadis T., Stefanidis I. Adaptation of renal function in heart failure. Ren. Fail. 2006; 28: 527-535.

104. Takahashi H., Yoshika M., Komiyama Y., Nishimura M. The central mechanism underlying hypertension: a review of the roles of sodium ions, epithelial sodium channels, the renin-angiotensin-aldosterone system, oxidative stress and endogenous digitalis in the brain. $\mathrm{Hy-}$ pertens. Res. 2011; 34: 1147-1160.

105. Fukiyama K., McCubbin J.W., Page I.H. Chronic hypertension elicited by infusion of angiotensin into vertebral arteries of unanaesthetized dogs. Clin. Sci. 1971; 40: 283-291.

106. Ha S.K. Dietary salt intake and hypertension. Electrolyte Blood Press. 2014; 12: 7-18.

107. Bock A. The influence of salt intake on hypertension. Ther. Umsch. 2009; 66: 721-724.

108. Dustan H.P., Valdes G., Bravo E.L., Tarazi R.C. Excessive sodium retention as a characteristic of salt-sensitive hypertension. Am. J. Med. Sci. 1986; 292: 67-74

109. Hou R., Liu Z., Liu J., Liu W., Wang Z., Geng T. The circadian rhythm of blood pressure and the effect of salt intake in salt-sensitive subjects. Chin. Med. J. (Engl). 2000; 113: 22-26.

110. Sullivan J.M. Salt sensitivity. Definition, conception, methodology, and long-term issues. Hypertension 1991; 17 (1 Suppl.): I61-68.

111. Uzu T., Ishikawa K., Fujii T., Nakamura S., Inenaga T., Kimura G. Sodium restriction shifts circadian rhythm of blood pressure from nondipper to dipper in essential hypertension. Circulation 1997; 96: 1859-1862.

112. Okuguchi T., Osanai T., Kamada T., Kimura M., Takahashi K., Okumura K. Significance of sympathetic nervous system in sodium-induced nocturnal hypertension. J. Hypertens. 1999; 17: 947-957.

113. Campese V.M., Romoff M.S., Levitan D., Saglikes Y., Friedler R.M., Massry S.G. Abnormal relationship between sodium intake and sympathetic nervous system activity in salt-sensitive patients with essential hypertension. Kidney Int. 1982; 21: 371-378.

114. Higashi Y., Oshima T., Watanabe M., Matsuura H., Kajiyama G. Renal response to $\mathrm{L}$-arginine in salt-sensitive patients with essential hypertension. Hypertension 1996; 27: 643-648.

115. Dziwura J., Bińczak-Kuleta A., Miazgowski T., Ziemak J., Widecka $\mathrm{K}$. The associations between G972R polymorphism of the IRS-1 gene, insulin resistance, salt sensitivity and non-dipper hypertension. Hypertens. Res. 2011; 34: 1082-1086.

116. Bankir L., Bochud M., Maillard M., Bovet P., Gabriel A., Burnier M. Nighttime blood pressure and nocturnal dipping are associated with daytime urinary sodium excretion in African subjects. Hypertension 2008; 51: 891-898.

117. Uzu T., Kimura G. Diuretics shift circadian rhythm of blood pressure from nondipper to dipper in essential hypertension. Circulation 1999; 100: 1635-1638.

118. Guyton A.C. Dominant role of the kidneys and accessory role of whole-body autoregulation in the pathogenesis of hypertension. Am. J. Hypertens. 1989; 2: 575-585.

119. Coffman T.M., Crowley S.D. Kidney in hypertension: guyton redux. Hypertension 2008; 51: 811-816.

120. Dorrington K.L., Pandit J.J. The obligatory role of the kidney in long-term arterial blood pressure control: extending Guyton's model of the circulation. Anaesthesia 2009; 64: 1218-1228.

121. Foundation N.K. K/DOQI clinical practice guidelines for chronic kidney disease: evaluation, classification, and stratification. Am. J. Kidney Dis. 2002; 39 (2 Suppl. 1): S1-266.

122. Fedecostante M., Spannella F., Cola G., Espinosa E., Dessì-Fulgheri P., Sarzani R. Chronic kidney disease is characterized by "double trouble" higher pulse pressure plus night-time systolic blood pressure and more severe cardiac damage. PLoS One 2014; 9: e86155.

123. Farmer C.K., Goldsmith D.J., Cox J., Dallyn P., Kingswood J.C., Sharpstone P. An investigation of the effect of advancing uraemia, renal replacement therapy and renal transplantation on blood pressure diurnal variability. Nephrol. Dial. Transplant. 1997; 12: 2301-2307.

124. Toussaint N.D., Lau K.K., Strauss B.J., Polkinghorne K.R., Kerr P.G. Associations between vascular calcification, arterial stiffness and bone mineral density in chronic kidney disease. Nephrol. Dial. Transplant. 2008; 23: 586-593.

125. Sezer S., Karakan S., Çolak T., Haberal M. Nocturnal nondipping hypertension is related to dyslipidemia and increased renal resistivity index in renal transplant patients. Transplant. Proc. 2011; 43: 530-532. 
126. Kimura G. Glomerular function reserve and sodium sensitivity. Clin. Exp. Nephrol. 2005; 9: 102-113.

127. Uzu T., Kazembe F.S., Ishikawa K., Nakamura S., Inenaga T., Kimura G. High sodium sensitivity implicates nocturnal hypertension in essential hypertension. Hypertension 1996; 28: 139-142.

128. Kimura G. Kidney and circadian blood pressure rhythm. Hypertension 2008; 51: 827-828.

129. Kobori H., Nangaku M., Navar L.G., Nishiyama A. The intrarenal renin-angiotensin system: from physiology to the pathobiology of hypertension and kidney disease. Pharmacol. Rev. 2007; 59: 251-287.

130. Schiffrin E.L. Effects of aldosterone on the vasculature. Hypertension 2006; 47: 312-318.

131. Birkenhäger A.M., van den Meiracker A.H. Causes and consequences of a non-dipping blood pressure profile. Neth. J. Med. 2007; 65: 127-131.

132. Portaluppi F., Cortelli P., Provini F., Plazzi G., Manfredini R., Lugaresi E. Alterations of sleep and circadian blood pressure profile. Blood Press. Monit. 1997; 2: 301-313.

133. Phillipson E.A. Control of breathing during sleep. Am. Rev. Respir. Dis. 1978; 118: 909-939.

134. Erden I., Erden E.C., Ozhan H. et al. Poor-quality sleep score is an independent predictor of nondipping hypertension. Blood Press. Monit. 2010; 15: 184-187.

135. Abate G., D’Andrea L., Battestini M., Zito M., Di Iorio A. Autonomic nervous activity in elderly dipper and non-dipper patients with essential hypertension. Aging (Milano) 1997; 9: 408-414.

136. Mellman T.A., Brown D.D., Jenifer E.S., Hipolito M.M., Randall O.S. Posttraumatic stress disorder and nocturnal blood pressure dipping in young adult African Americans. Psychosom. Med. 2009; 71: 627-630.

137. Grassi G., Trevano F.Q., Seravalle G., Scopelliti F., Mancia G. Baroreflex function in hypertension: consequences for antihypertensive therapy. Prog. Cardiovasc. Dis. 2006; 48: 407-415.

138. Turgut F., Bayrak O., Kanbay M. et al. Circadian rhythm of blood pressure in patients with benign prostatic hyperplasia. Scand. J. Urol. Nephrol. 2008; 42: 47-52.

139. Natsume O. A clinical investigation of nocturnal polyuria in patients with nocturia: a diurnal variation in arginine vasopressin secretion and its relevance to mean blood pressure. J. Urol. 2006; 176: 660-664

140. Suzuki M., Guilleminault C., Otsuka K., Shiomi T. Blood pressure "dipping" and "non-dipping" in obstructive sleep apnea syndrome patients. Sleep 1996; 19: 382-387.
141. Nabe B., Lies A., Pankow W., Kohl F.V., Lohmann F.W. Determinants of circadian blood pressure rhythm and blood pressure variability in obstructive sleep apnoea. J. Sleep Res. 1995; 4: 97-101.

142. Julius S., Pascual A.V., London R. Role of parasympathetic inhibition in the hyperkinetic type of borderline hypertension. Circulation 1971; 44: 413-418.

143. Fletcher E.C., Miller J., Schaaf J.W., Fletcher J.G. Urinary catecholamines before and after tracheostomy in patients with obstructive sleep apnea and hypertension. Sleep 1987; 10: 35-44.

144. Narkiewicz K., van de Borne P.J., Montano N., Dyken M.E., Phillips B.G., Somers V.K. Contribution of tonic chemoreflex activation to sympathetic activity and blood pressure in patients with obstructive sleep apnea. Circulation 1998; 97: 943-945.

145. Chen J., He L., Dinger B., Fidone S. Cellular mechanisms involved in rabbit carotid body excitation elicited by endothelin peptides. Respir Physiol. 2000; 121: 13-23.

146. Chen J., He L., Dinger B., Stensaas L., Fidone S. Role of endothelin and endothelin A-type receptor in adaptation of the carotid body to chronic hypoxia. Am. J. Physiol. Lung Cell Mol. Physiol. 2002; 282: L1314-1323.

147. Wolf J., Hering D., Narkiewicz K. Non-dipping pattern of hypertension and obstructive sleep apnea syndrome. Hypertens. Res. 2010; 33: 867-871.

148. Bayram N.A., Ciftci B., Keles T. et al. Endothelial function in normotensive men with obstructive sleep apnea before and 6 months after CPAP treatment. Sleep 2009; 32: 1257-1263.

149. Lozano L., Tovar J.L., Sampol G. et al. Continuous positive airway pressure treatment in sleep apnea patients with resistant hypertension: a randomized, controlled trial. J. Hypertens. 2010; 28: 2161-2168

150. de Paula Soares C.F., Cavichio L., Cahali M.B. Lateral pharyngoplasty reduces nocturnal blood pressure in patients with obstructive sleep apnea. Laryngoscope 2014; 124: 311-316.

151. Staessen J.A., Bieniaszewski L., O’Brien E. et al. Nocturnal blood pressure fall on ambulatory monitoring in a large international database. The 'Ad Hoc' Working Group. Hypertension 1997; 29: 30-39.

152. Prinz P.N., Vitiello M.V., Raskind M.A., Thorpy M.J. Geriatrics: sleep disorders and aging. N. Engl. J. Med. 1990; 323: 520-526.

153. Kohara K., Igase M., Maguchi M., Fukuoka T., Kitami Y., Hiwada $\mathrm{K}$. Autonomic nervous function in essential hypertension in the elderly. Evaluation by power spectral analysis of heart rate variability. Am. J. Hypertens. 1996; 9: 1084-1089. 